\title{
Resuscitative endovascular balloon occlusion of the aorta for uncontrollable nonvariceal upper gastrointestinal bleeding
}

\author{
Hidefumi Sano ${ }^{1}$, Junya Tsurukiri ${ }^{*}$, Akira Hoshiai', Taishi Oomura', Yosuke Tanaka ${ }^{1}$ and Shoichi Ohta ${ }^{2}$
}

\begin{abstract}
Background: Although resuscitative endovascular balloon occlusion of the aorta (REBOA) in various clinical settings was found to successfully elevate central blood pressure in hemorrhagic shock, this intervention is associated with high mortality and may represent a last-ditch option for trauma patients. We conducted a retrospective study of patients with nonvariceal upper gastrointestinal bleeding (UGIB) who underwent REBOA to identify the effectiveness of REBOA and reviewed published literatures.
\end{abstract}

Methods: REBOA were performed by trained acute care physicians in the emergency room and intensive care unit. The deployment of balloon catheters was positioned using ultrasonography guidance. Collected data included clinical characteristics, hemorrhagic severity, blood cultures, metabolic values, blood transfusions, REBOA-related complications and mortality. A literature search using PUBMED to include "aortic occlusion" and "gastrointestinal bleeding" was conducted.

Results: REBOA was attempted in eight patients among 140 patients with UGIB and median age was 66 years. Systolic blood pressure significantly increased after REBOA ( $66 \pm 20$ vs. $117 \pm 45 \mathrm{mmHg}, p<0.01)$ and the total occlusion time of REBOA was $80 \pm 48 \mathrm{~min}$. Strong positive correlations were found between total occlusion time of REBOA and lactate concentration (Spearman's $r=0.77$ ), clinical Rockwall score (Spearman's $r=0.80$ ), and age (Spearman's $r=0.88$ ), respectively.

Conclusion: REBOA can be performed with a high degree of technical success and is effective at improving hemodynamic in patients with UGIB. Correlations between total occlusion time and high lactate levels, clinical Rockall score, and age may be important for successful use of REBOA.

\section{Background}

Uncontrollable hemorrhage is a main cause of death in patients with hemorrhagic shock admitted to the emergency department (ED) or intensive care unit (ICU), and trauma and nonvariceal upper gastrointestinal bleeding (UGIB) are the most common causes of massive hemorrhage in acute care setting [1,2]. Although main aim of resuscitation is to stop the source of hemorrhage and restore hemodynamics, persistent hemorrhage can be rapidly fatal. The options for impending cardiac collapse are resuscitative thoracotomy and aortic clamping immediately performed in such cases [3].

\footnotetext{
* Correspondence: junya99@tokyo-med.ac.jp

${ }^{1}$ Emergency and Critical Care Medicine, Tokyo Medical University Hachioji

Medical Center, 1163 Tatemachi, Hachioji, Tokyo 193-0998, Japan

Full list of author information is available at the end of the article
}

A recent systematic review of REBOA in various clinical settings was found to successfully elevate central blood pressure in hemorrhagic shock [4]. Although, REBOA is increasingly used as an alternative to resuscitative thoracotomy, a recent report suggested that REBOA was associated with increased mortality and may represent a last-ditch option for trauma patients with hemodynamic instability in Japan [5]. However, there are no satisfactory reports regarding the effectiveness of REBOA among patients with UGIB. Therefore, we conducted a retrospective study of patients with UGIB who underwent REBOA at a single emergency center to evaluate the effectiveness of REBOA. In addition, we reviewed the published literature to provide a summary of the experience data. 


\section{Methods}

\section{Patients}

The ethics committee of Tokyo Medical University Hachioji Medical Center approved the design of this retrospective study. UGIB patients with suspected hemorrhagic shock who subsequently underwent REBOA in the ER or who were admitted to our intensive care unit (ICU) and subsequently developed hemorrhagic shock and underwent REBOA in the ICU were enrolled in this study between September 2011 and April 2015. Patients with a systolic blood pressure (SBP) $<90 \mathrm{mmHg}$ or a shock index (SI; ratio of heart rate to SBP) $\geq 1.0$ were considered to be in shock. We excluded patients aged $<15$ years and those who had cardiac arrest on admission or were diagnosed with any terminal disease during the study period.

\section{Intervention}

Patients with hemorrhagic shock in the transient- and nonresponse groups were considered to be hemodynamically unstable on the basis of their response to an initial fluid resuscitation with $1 \mathrm{~L}$ of Ringer's lactate. Although it is important to administer blood and blood products as soon as possible for trauma or non-trauma shock patients, the preparation of blood or blood products takes time in Japan, at least in our hospital. Consequently, the empirical transfusion of blood and blood products was initiated as soon as possible. REBOA was initiated by one or two acute care physicians in patients showing hemodynamic instability and an inability to remain normotensive following resuscitation. In our department, one acute care physician (TJ) was trained for $\geq 1$ year as a member of the endovascular team in the Radiology Department of another university hospital, whereas all other acute care physicians in our ER performed REBOA under the guidance of TJ.

For the REBOA procedure, a $10 \mathrm{Fr}$. Intra-aortic balloon occlusion (IABO) catheters (BLOCK BALLOON ${ }^{\mathrm{Tm}}$; Senko Medical Instrument, Tokyo, Japan) or 7 Fr. IABO catheters (RESCUE BALLOONं ${ }^{\oplus}$ Tokai Medical Products, Tokyo, Japan) have been available in our ER and ICU. These are a double lumen balloon catheter with a stainless steel styled. For percutaneous deployment of IABO catheters, all necessary guidewires, sharps and introducers are packaged together in the kit. An acute care physician first inserts 7 Fr. or 10 Fr. sheath into the femoral artery using the Seldinger method. After insertion of the femoral artery sheath, the IABO catheter was placed into the aorta and REBOA was performed. IABO catheter was placed into the aorta, with selection of the aortic zone for occlusion according to the recommendations of Stannard et al. under ultrasonography guidance [6]. Placement of the balloon is normally performed in Zone I (proximal of the aorta, origin of the left subclavian artery to the celiac artery) in patients with suspected UGIB. IABO catheter positioning was performed under ultrasonography guidance before REBOA placement and confirmed by portable chest radiography in ER (Fig. 1) [7].

\section{Data collection}

The following characteristics were noted from the charts and radiographs of the patients with hemodynamic instability: age, sex, vital signs, Acute Physiology and Chronic Health Evaluation (APACHE) II score, hemorrhagic severity, blood cultures, metabolic and coagulation values $[\mathrm{pH}$, lactate concentration, base excess $(\mathrm{BE})$, prothrombin time, and activated partial thrombin time], blood transfusion, REBOA-related complications and mortality. Hemorrhagic severity was evaluated using SI and severity of UGIB was evaluated at the onset using the Glasgow-Blatchford bleeding score (GBS), clinical Rockall score (CRS) and AIMS65 score [8]. In patients admitted to ER or ICU, blood cultures and metabolic and coagulation values were measured at the beginning of resuscitative interventions. Markers of end-organ dysfunction included serum aspartate transaminase (AST), blood urea nitrogen (BUN), creatinine, potassium, sodium, total bilirubin, lactate dehydrogenase $(\mathrm{LDH})$, and creatine kinase $(\mathrm{CK})$ as described in previous reports thoroughly reviewed by two acute care

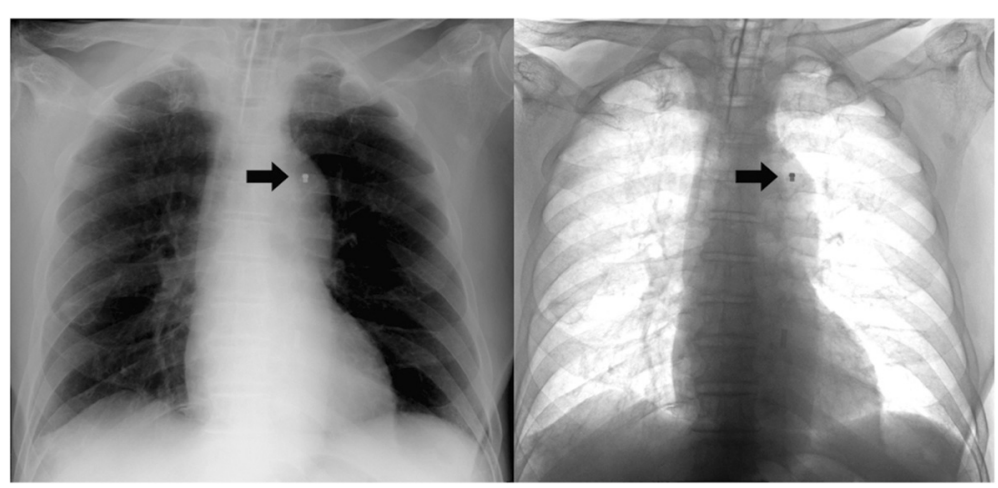

Fig. 1 Placement of the balloon is performed in Zone I (Patient 5). The tip of IABO catheter (arrow) 
Table 1 Clinical characteristics of the patients

\begin{tabular}{|c|c|c|c|c|c|c|c|c|}
\hline Variables & Patient 1 & Patient 2 & Patient 3 & Patient 4 & Patient 5 & Patient 6 & Patient 7 & Patient 8 \\
\hline Age (y) & 69 & 36 & 83 & 64 & 78 & 69 & 50 & 79 \\
\hline Sex & male & male & male & male & male & male & male & male \\
\hline Body temperature $\left({ }^{\circ} \mathrm{C}\right)$ & 35.5 & 36.2 & 36.8 & 37.3 & 36.0 & 37.0 & 36.1 & 35.7 \\
\hline \multicolumn{9}{|l|}{ Hemodynamics } \\
\hline Shock index & 2.3 & 0.8 & 2.1 & 2 & 0.8 & 1.7 & 1.1 & 1.3 \\
\hline SBP pre-REBOA (mmHg) & 60 & 90 & 96 & 54 & 41 & 63 & 61 & - \\
\hline SBP post REBOA (mmHg) & 97 & 111 & 206 & 74 & 82 & 112 & 140 & - \\
\hline$\Delta \mathrm{SBP}(\mathrm{mmHg})$ & 37 & 21 & 110 & 20 & 41 & 49 & 79 & - \\
\hline APACHE ॥ & 22 & 7 & 26 & 31 & 22 & 26 & 21 & 30 \\
\hline \multicolumn{9}{|l|}{ Severity of upper gastrointestinal bleeding } \\
\hline Glasgow Blatchford bleeding score & 17 & 7 & 19 & 11 & 14 & 13 & 12 & 17 \\
\hline Clinical Rockall score & 3 & 3 & 4 & 3 & 5 & 3 & 2 & 3 \\
\hline AlM 65 score & 3 & 0 & 4 & 3 & 2 & 5 & 0 & 2 \\
\hline \multicolumn{9}{|l|}{ Initial blood values } \\
\hline White blood cell count $(/ \mu \mathrm{L})$ & 12900 & 13600 & 24000 & 17300 & 9120 & 10600 & 11500 & 7170 \\
\hline Hemoglobin (g/dL) & 5.5 & 14.8 & 11.2 & 7.3 & 5 & 5.3 & 8.8 & 6.1 \\
\hline Hematocrit (\%) & 16 & 44 & 31 & 21 & 15 & 16 & 26 & 19 \\
\hline Platelet connt $\left(\times 10^{4} / \mathrm{mL}\right)$ & 11.9 & 34.6 & 9.3 & 36.8 & 17.3 & 12.2 & 36 & 22.9 \\
\hline BUN (mg/dL) & 18.7 & 21.1 & 62.1 & 8.2 & 44.1 & 13.9 & 46.9 & 32.0 \\
\hline Lactate (mmol/L) & 11.1 & 1.3 & 9.6 & 5.6 & 15.8 & 6.6 & 63 & 15.0 \\
\hline $\mathrm{pH}$ & 7.25 & 7.36 & 7.38 & 6.94 & 7.35 & 7.24 & 7.30 & 6.96 \\
\hline Base excess (mmol/L) & 0.1 & -2.5 & -11.5 & -14.5 & -14.6 & -9.3 & -9.4 & -21.8 \\
\hline Prothrombin time (\%) & 51 & 113 & 64 & 62 & 83 & 51 & 105 & 62 \\
\hline APTT (sec) & 64.5 & 30.1 & 35.3 & 240 & 64.3 & 123.9 & 33.4 & - \\
\hline Diagnosis & Gastric ulcer & Gastric ulcer & Duodenum ulcer & Anastomotic bleeding & Duodenum ulcer & Left gastric artery aneurysm & Duodenum ulcer & Esophageal cancer \\
\hline Definitive hemostatic control & endoscopy & endoscopy & endoscopy & $\mathrm{AE}$ & AE (failed endoscopy) & AE (failed endoscopy) & AE (failed endoscopy) & $\mathrm{AE}$ \\
\hline CPA during procedures & no & no & no & yes & no & yes & no & no \\
\hline
\end{tabular}


Table 1 Clinical characteristics of the patients (Continued)

\begin{tabular}{|c|c|c|c|c|c|c|c|c|}
\hline \multicolumn{9}{|c|}{ Blood and blood product transfusion within $24 \mathrm{~h}(\mathrm{~mL})$} \\
\hline PRBC & 1400 & 280 & 1960 & 2520 & 1960 & 2800 & 3080 & 1680 \\
\hline FFP & 1200 & 0 & 1200 & 1680 & 2160 & 1920 & 1920 & 720 \\
\hline Re-bleeding & no & no & no & no & yes & yes & no & no \\
\hline \multicolumn{9}{|l|}{ REBOA } \\
\hline Total occlusion time (min) & 57 & 20 & 140 & 54 & 145 & 95 & 50 & Failure \\
\hline REBOA-related complication & none & none & none & none & none & none & none & none \\
\hline Outcome within 30 days & Alive & Alive & Alive & Alive & Died $<24 \mathrm{~h}$ & Alive & Alive & Died $<24 \mathrm{~h}$ \\
\hline
\end{tabular}
angioembolization, CPA cardiopulmonary arrest, $P R B C$ packed red blood cells, and FFP fresh-frozen plasma 
physicians ( $\mathrm{SH}$ and TJ) $[9,10]$. These values were measured within $12 \mathrm{~h}$ after definitive hemostasis. The REBOA-related complications included vessel injuries (i.e., aortic dissection, rupture, perforation, pseudo-aneurysm, and arteriovenous fistula), groin hematoma, embolization, air emboli, peripheral ischemia, and organ dysfunction.

\section{Literature search}

A literature search using PUBMED to include "aortic occlusion" and "gastrointestinal bleeding" was conducted. Original articles and case reports published in English language were reviewed, and follow-up references listed were further investigated.

\section{Statistical analyses}

Data from all eligible patients were analyzed. Continuous variables are shown as mean values with standard deviation in text and median and interquartile range in Tables. Between-group differences were statistically assessed using the Mann-Whitney $U$ test for continuous variables, paired $t$ test for continuous dependent variables and the Fisher's exact test for categorical variables. The Spearman correlation coefficient was used to identify correlations between the evaluated parameters. All statistical analyses were performed using Prism version 6.0a statistical software (GraphPad Software, San Diego, CA, USA). Categorical variables were calculated as the ratio (percentage) of the frequency of occurrence. A probability $(p)$ value of $>0.05$ was considered statistically significant.

\section{Results}

\section{Demographics and clinical characteristics}

REBOA was attempted in eight patients among 140 patients with UGIB. The mean age was $66 \pm 16$ years, and all of the patients were male. The mean SI, GBS, CRS, AIMS65 score and APACHE II were $1.5 \pm 0.6,16 \pm 4,3 \pm$ $1,2 \pm 2$, and $23 \pm 7$, respectively. The demographics and clinical characteristics of all patients are shown in Table 1. Placement of the IABO catheter failed in one patient aged 79 years with severe aortic calcifications. Definitive hemostasis was endoscopy in 3 cases, anigo-embolization (AE) in 2 cases, and AE after failed endoscopy in 3 cases, respectively. The total occlusion time of REBOA was $80 \pm$ $48 \mathrm{~min}$ in this study. The mean volume of packed red blood cells, fresh frozen plasma and Ringer's lactate administered during the resuscitation were $2000 \pm 949 \mathrm{~mL}$, $1440 \pm 733 \mathrm{~mL}$, and $4000 \pm 2363 \mathrm{~mL}$, respectively. The mortality rates within $24 \mathrm{~h}$ and 30 days were $15 \%$ each. No REBOA-related complications were encountered.

\section{Changes in acute care management with REBOA}

Systolic blood pressure was significantly higher after initiating of REBOA ( $66 \pm 20$ vs. $117 \pm 45 \mathrm{mmHg}, p<0.01$ ). Heart rate, lactate concentration, and $\mathrm{BE}$ were not significantly different between before and after REBOA. Initial serum concentration of AST, BUN, creatinine, CK, potassium, sodium, total bilirubin, white blood cell counts, and C-reactive response were not significantly different compared with those after completion of hemostasis. The serum concentration of LDH following REBOA was significantly higher than that before REBOA ( $227 \pm 154$ vs. $595 \pm 406 \mathrm{IU} / \mathrm{L}, p=0.04$ ) (Table 2).

\section{Correlations between total occlusion time and vital indicators}

Strong positive correlations were found between total occlusion time and lactate concentration (Spearman's $r=0.77, p=0.04$ ), CRS (Spearman's $r=0.80, p=0.03$ ), and age (Spearman's $r=0.88, p<0.01$ ), respectively (Fig. 2).

\section{Discussion}

REBOA is an adjunct procedure designed to sustain the circulation until definitive hemostasis is obtained.

Upon review of the existing literature, it was evident that there are only a very limited number of publications related to REBOA treatment for UGIB, and only four case references were retrieved. We identified 4 published reports involving 4 patients (1 patient per 1 report) with hemodynamic instability caused by UIGB. Among them, 2

Table 2 Comparison of the vital indicators between before and after REBOA

\begin{tabular}{|c|c|c|}
\hline Vital indicators, median (IQR) & $\begin{array}{l}\text { Before REBOA } \\
(n=7)\end{array}$ & After REBOA $(n=7)$ \\
\hline $\begin{array}{l}\text { Systolic blood pressure } \\
(\mathrm{mmHg})\end{array}$ & $61(57-77)$ & $111(90-126)^{*}$ \\
\hline Heart rate (beat/min) & $126(112-131)$ & $123(113-127)$ \\
\hline White blood cells $(/ \mu \mathrm{L})$ & $\begin{array}{l}12100(11050- \\
14250)\end{array}$ & $\begin{array}{l}16600(13950- \\
17900)\end{array}$ \\
\hline Hemoglobin (g/dL) & $7.3(5.4-10)$ & $9.7(8.7-10.6)$ \\
\hline Platelet $\left(\times 10^{4} / \mu \mathrm{L}\right)$ & $17.3(12.1-35.3)$ & $10.3(7.2-13.6)$ \\
\hline Prothrombin time (\%) & $64(57-94)$ & $56(50-70)$ \\
\hline Lactate (mmol/L) & $3.2(2.9-6.0)$ & $5.4(4.3-7.0)$ \\
\hline Base excess (mmol/L) & $-11.5(-14.6--8.7)$ & $-3.1(-4.8--1.4)$ \\
\hline Blood urea nitrogen $(\mathrm{mg} / \mathrm{dL})$ & $21.1(16.3-45.5)$ & $30.8(16.6-38.8)$ \\
\hline Creatinine (mg/dL) & $0.97(0.90-1.03)$ & $1.14(0.83-1.29)$ \\
\hline Aspartate transaminase $(\mathrm{U} / \mathrm{L})$ & $14(11.5-43.5)$ & $101(64.5-608)$ \\
\hline Total bilirubin (mg/dL) & $0.40(0.35-0.6)$ & $0.60(0.45-0.80)$ \\
\hline Potassium (mmol/L) & $4.0(3.8-4.1)$ & $3.5(3.5-4.2)$ \\
\hline Sodium (mmol/L) & $138(135-139)$ & $137(136-141)$ \\
\hline Creatine kinase $(U / L)$ & $56(47-80)$ & $263(109-620)$ \\
\hline Alkaline phosphatase (U/L) & $191(153-197)$ & 137 (104-249) \\
\hline Lactate dehydrogenase $(U / L)$ & $158(123-285)$ & $411(328-862)^{*}$ \\
\hline C reactive protein $(\mathrm{mg} / \mathrm{dL})$ & $1.61(0.55-2.64)$ & $1.07(0.70-3.55)$ \\
\hline
\end{tabular}

$I Q R$ interquartile range, $R E B O A$, resuscitative endovascular balloon occlusion of the aorta; ${ }^{*}=p<0.05$ vs. Before REBOA 


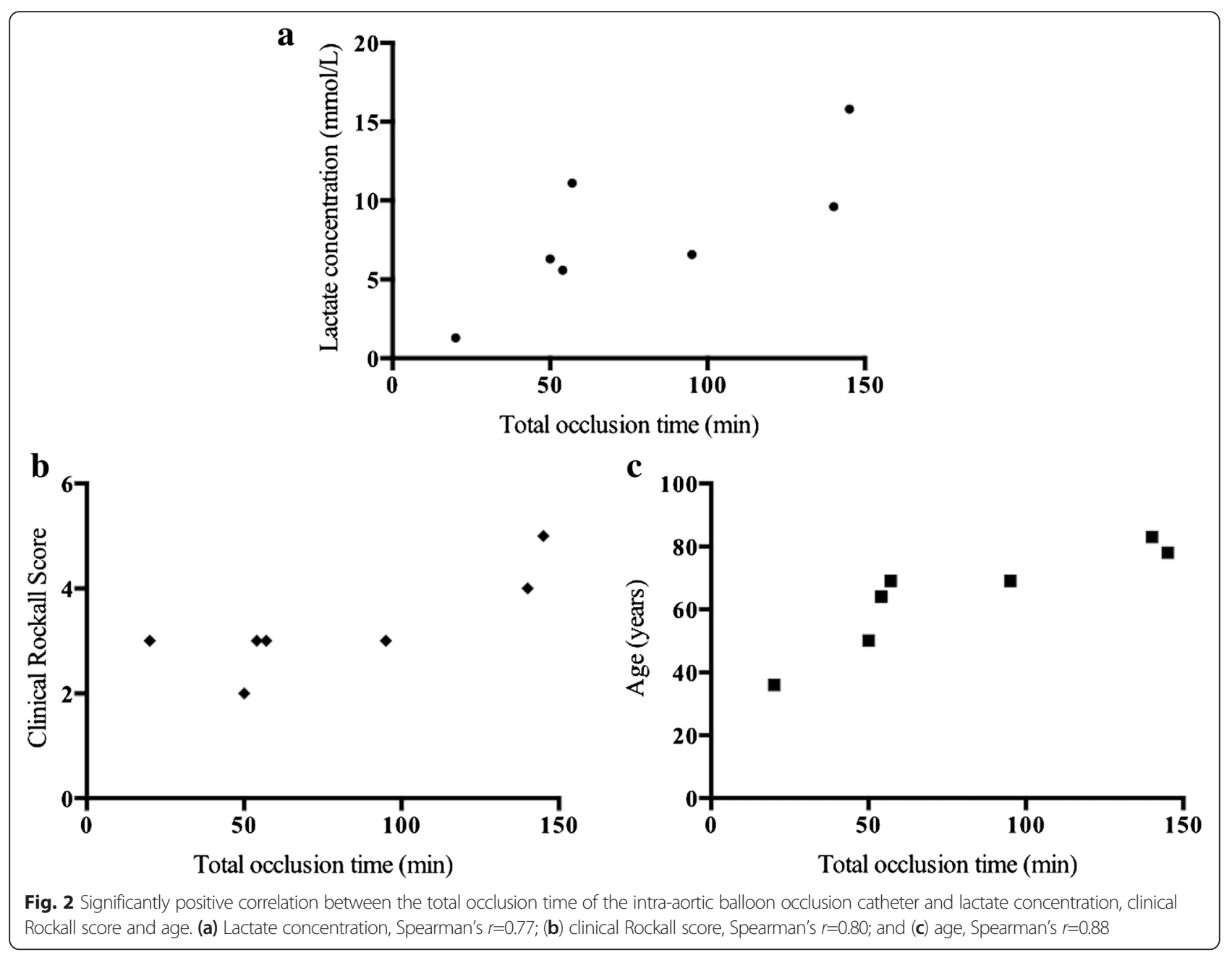

patients underwent REBOA for duodenum ulcers, one child for aorta-esophageal fistula, and one for unknown UGIB [11-14]. Table 3 showed the clinical characteristics. Placement of the balloon was in Zone I without fluoroscopy and hemodynamics have improved in all cases. There was no REBOA-related complication and the mortality rate was $25 \%$. To the best of our knowledge, the present study represents the first retrospective study to evaluate the utility of REBOA among patients with UGBI.

In the present study, our trained acute care physicians could achieve REBOA procedures in the ED/ICU with a high degree of technical success. Blood pressure following REBOA did significantly increased compared with that before REBOA, and no significant differences detected between patients with UGIB in terms of almost all markers of end-organ dysfunction. A recent study reported a REBOA duration of $>90 \mathrm{~min}$ in an animal model of hemorrhageinduced organ dysfunction, particularly that of the kidneys and liver. Our results were consistent with those reported by Markov et al. [9]. We also found clinically significant correlations between the total occlusion time of REBOA and lactate concentration and CRS measured at the beginning of resuscitation among patients with UGIB. Conventionally, these parameters are used to confirm a suspected massive hemorrhage and permit the earlier achievement of hemostasis or administration of massive transfusion if required [15]. Thus, it is very important to shorten the time from ED arrival to initiation of hemostatic procedures before hemodynamic collapse as much as possible. Although endoscopic treatment for UGIB is generally acceptable, it can be difficult to achieve complete hemostasis in some patients with a high lactate concentration and/or CRS. Excessive hemorrhage may rapidly become fatal and can be challenging to secure. In addition, it makes maintaining a visual field during endoscopy difficult. These complications result in significant time delays during procedures. In the present study, one patient (Patient No. 2) who had a transient response to initial resuscitation had his systolic blood pressure decrease to $80 \mathrm{mmHg}$. It was then decided to place an IABO catheter prior to endoscopic treatment, and an IABO catheter was promptly inserted at ED. His blood pressure subsequently increased 
Table 3 Literature review

\begin{tabular}{|c|c|c|c|c|c|c|c|c|c|c|c|c|c|c|c|c|c|}
\hline & Author & $\begin{array}{l}\text { Year of } \\
\text { publication }\end{array}$ & $\begin{array}{l}\text { Study } \\
\text { type }\end{array}$ & $\begin{array}{l}\text { Number } \\
\text { of } \\
\text { patient }\end{array}$ & $\begin{array}{l}\text { Age } \\
\text { (years) }\end{array}$ & Sex & Diagnosis & CPA & $\begin{array}{l}\text { Sheath } \\
\text { (Fr.) }\end{array}$ & $\begin{array}{l}\text { Insertion } \\
\text { method }\end{array}$ & $\begin{array}{l}\text { Use } \\
\text { fluoroscopy }\end{array}$ & $\begin{array}{l}\text { Position } \\
\text { (Zone) }\end{array}$ & $\begin{array}{l}\text { Intervals for } \\
\text { REBOA } \\
\text { (min) }\end{array}$ & $\begin{array}{l}\text { Hemodynam } \\
\text { ics (SBP) }\end{array}$ & Complications & $\begin{array}{l}\text { Definitive } \\
\text { hemostatic } \\
\text { control }\end{array}$ & Outcome \\
\hline 1 & $\begin{array}{l}\text { Low et } \\
\text { al. [11] }\end{array}$ & 1986 & $\begin{array}{l}\text { case } \\
\text { series }\end{array}$ & 1 & NA & NA & $\begin{array}{l}\text { mesenteric } \\
\text { thrombosis }\end{array}$ & yes & 11.5 & cutdown & no & NA & NA & improved & NA & NA & Dead \\
\hline 2 & $\begin{array}{l}\text { Karkos et } \\
\text { al. [12] }\end{array}$ & 2001 & $\begin{array}{l}\text { case } \\
\text { report }\end{array}$ & 1 & 36 & female & $\begin{array}{l}\text { duodenum } \\
\text { ulcer }\end{array}$ & no & NA & cutdown & no & I & 30 & $\begin{array}{l}70 \rightarrow \\
140 \mathrm{mmHg}\end{array}$ & none & surgery & Alive \\
\hline 3 & $\begin{array}{l}\text { Hill et al. } \\
\text { [13] }\end{array}$ & 2010 & $\begin{array}{l}\text { case } \\
\text { report }\end{array}$ & 1 & 9 & female & $\begin{array}{l}\text { aortoesophageal } \\
\text { fistula }\end{array}$ & yes & 7 & percutaneous & no & 1 & NA & improved & none & stent graft & Alive \\
\hline 4 & $\begin{array}{l}\text { Shigesato } \\
\text { et al. [14] }\end{array}$ & 2015 & $\begin{array}{l}\text { case } \\
\text { report }\end{array}$ & 1 & 79 & female & $\begin{array}{l}\text { duodenum } \\
\text { ulcer }\end{array}$ & yes & 9 & percutaneous & no & I & 150 & $\begin{array}{l}40 \rightarrow 240 \\
\mathrm{mmHg}\end{array}$ & none & surgery & Alive \\
\hline
\end{tabular}


following balloon inflation, and he underwent endoscopic treatment at ED. The bleeding vessel was visualized from the ulcer at the gastric angle, and the bleeding was arrested using balloon inflation. We believe that this case denotes the effectiveness of a balloon-assisted hemostatic technique in decreasing bleeding to secure a visual field and to reduce the volume of blood transfusion.

The immediately availability of an IABO catheter and the earlier introduction of REBOA have enabled us to sustain the circulation as an adjunct procedure until definitive hemostasis is attained. A formal algorithm that is utilized in a prospective manner is essential for UGIB treatment (endoscopy, $\mathrm{AE}$, and surgery) and may shorten the occlusion time of REBOA. In the present study, one patient (Patient No. 5) with failed endoscopic hemostasis died within $24 \mathrm{~h}$; the total occlusion time was $145 \mathrm{~min}$. Although, REBOA for $60 \mathrm{~min}$ was reportedly to be well tolerated in an animal model of uncontrolled hemorrhagic shock, a recent report has suggested that partial REBOA could increase the survival time to 180 min while maintaining central blood pressure and carotid blood flow $[10,16]$. In future, this method may be helpful for successful use of REBOA in patients with a high lactate concentration and a high CRS.

The major complications observed with REBOA included vessel injuries (i.e. aortic dissection, rapture and perforation), embolization, and peripheral ischemia. Recent reports have reported no vessel injuries caused by an IABO catheter or inflated balloon in trauma patients [17]. We routinely use ultrasonography to guide positioning of the IABO catheter during procedures and evaluate balloon placement using portable radiography after catheter deployment and there was no REBOArelated complications. Giuliani et al. support this result in the study showing that ultrasonography alone is safe and accurate as fluoroscopy for positioning and deployment of an IABO catheter [7].

However, this study has several limitations, particularly the small number of evaluated patients. Second, this was not a randomized, controlled trial because in the acute care setting, it is difficult to perform a randomized trial in a single emergency center. Furthermore, use of a propensity score is not suitable for a small sample size. Thus, large multi-institutional studies are essential for further evaluating the utility of REBOA against UGIB. Third, patients were allocated to REBOA use and treatments according to the decision of the attending lead acute care physicians, and this should be considered when interpreting our outcomes. Although patient selection was carefully performed, we believe the number of patients could have been greater. Consequently, our methods may be evaluated and incorporated into future studies to optimize the criteria for patient selection. Finally, application of this approach in other emergency centers may be limited by a lack of resources.

\section{Conclusion}

Immediate availability of an IABO catheter device can perform REBOA in ER and ICU and achieve a high degree of technical success. Temporary aortic balloon occlusion is effective at improving hemodynamics and perfusion in patients with UGIB. Furthermore, the correlations of total occlusion time and high clinical Rockall score, as the most relevant one, lactate levels, and advanced age may be important for successful use of REBOA. Formal prospective study is warranted to clarify the role of this adjunct procedure in UGIB treatment.

\section{Abbreviations}

AE: angio-embolization; APACHE: acute physiology and chronic health evaluation; AST: aminotransferases; BE: base excess; BUN: blood urea nitrogen; CK: creatine kinase; CRS: clinical rockall score; ED: emergency department; GBS: Glasgow-Blatchford bleeding score; IABO: intra-aortic balloon occlusion; LDH: lactate dehydrogenase; REBOA: resuscitative endovascular balloon occlusion of the aorta; SBP: systolic blood pressure; SI: shock index; UGIB: upper gastrointestinal bleeding.

\section{Competing interests}

None. This manuscript has not been published previously and is not under consideration for publication elsewhere.

\section{Authors' contributions}

SH and TJ: conceived and designed the study, collected date and data interpretation. HA, OT and TY: data interpretation. OS: data interpretation and final approval of the version to be submitted. All authors read and approved the final manuscript.

\section{Acknowledgments}

The authors would like to thank Enago (www.enago.jp) for the English language review.

\section{Author details}

${ }^{1}$ Emergency and Critical Care Medicine, Tokyo Medical University Hachioji Medical Center, 1163 Tatemachi, Hachioji, Tokyo 193-0998, Japan.

Emergency and Disaster Medicine, Tokyo Medical University, 6-7-1 Nishi-shinjuku, Shinjuku, Tokyo 160-0023, Japan.

Received: 2 March 2016 Accepted: 10 May 2016

Published online: 20 May 2016

References

1. Dries DJ. The contemporary role of blood products and components used in trauma resuscitation. Scand J Trauma Resusc Emerg Med. 2010;18:63. doi: 10.1186/1757-7241-18-63.

2. Baracat F, Moura E, Bernardo W, Pu LZ, Mendonça E, Moura D, et al. Endoscopic hemostasis for peptic ulcer bleeding: systematic review and meta-analyses of randomized controlled trials. Surg Endosc. 2015. Epub ahead of print.

3. Rabinovici R, Bugaev N. Resuscitative thoracotomy: an update. Scand J Surg. 2014;103:112-9.

4. Morrison JJ, Galgon RE, Jansen JO, Cannon JW, Rasmussen TE, Eliason JL. A systematic review of the use of resuscitative endovascular balloon occlusion of the aorta in the management of hemorrhagic shock. J Trauma Acute Care Surg. 2016;80:324-34. doi:10.1097/TA.0000000000000913.

5. Norii T, Crandall C, Terasaka Y. Survival of severe blunt trauma patients treated with resuscitative endovascular balloon occlusion of the aorta compared with propensity score-adjusted untreated patients. J Trauma Acute Care Surg. 2015;78:721-8. doi:10.1097/TA.0000000000000578.

6. Stannard A, Eliason JL, Rasmussen TE. Resuscitative endovascular balloon occlusion of the aorta (REBOA) as an adjunct for hemorrhagic shock. J Trauma. 2011;71:1869-72. doi:10.1097/TA.0b013e31823fe90c.

7. Guliani S, Amendola M, Strife B, Morano G, Elbich J, Albuquerque F, et al. Central aortic wire confirmation for emergent endovascular procedures: as 
fast as surgeon-performed ultrasound. J Trauma Acute Care Surg. 2015;79: 549-54. doi:10.1097/TA.0000000000000818.

8. Jung SH, Oh JH, Lee HY, Jeong JW, Go SE, You CR, et al. Is the AlMS65 score useful in predicting outcomes in peptic ulcer bleeding? World J

Gastroenterol. 2014;20:1846-51. doi:10.3748/wjg.v20.i7.1846

9. Markov NP, Percival TJ, Morrison JJ, Ross JD, Scott DJ, Spencer JR, et al. Physiologic tolerance of descending thoracic aortic balloon occlusion in a swine model of hemorrhagic shock. Surgery. 2013;153:848-56. doi:10.1016/j. surg.2012.12.001.

10. Scott DJ, Eliason JL, Villamaria C, Morrison JJ, Houston 4th R, Spencer JR, et al. A novel fluoroscopy-free, resuscitative endovascular aortic balloon occlusion system in a model of hemorrhagic shock. J Trauma Acute Care Surg. 2013;75:122-8.

11. Low RB, Longmore W, Rubinstein R, Flores L, Wolvek S. Preliminary report on the use of the percluder occluding aortic balloon in human beings. Ann Emerg Med. 1986;15:1466-9.

12. Karkos $C D$, Bruce IA, Lambert ME. Use of the intra-aortic balloon pump to stop gastrointestinal bleeding. Ann Emerg Med. 2001;38:328-31.

13. Hill SJ, Zarroug AE, Ricketts RR, Veeraswamy R. Bedside placement of an aortic occlusion balloon to control a ruptured aorto-esophageal fistula in a small child. Ann Vasc Surg. 2010;24:822.e7-9. doi:10.1016/j.avsg.2009.12.016.

14. Shigesato S, Shimizu T, Kittaka T, Akimoto H. Intra-aortic balloon occlusion catheter for treating hemorrhagic shock after massive duodenal ulcer bleeding. Am J Emerg Med. 2015;33:473.e1-2. doi:10.1016/j.ajem.2014.01.024

15. Bozkurt S, Köse A, Arslan ED, Erdoğan S, Uçbilek E, Cevik I, et al. Validity of modified early warning, Glasgow Blatchford, and pre-endoscopic Rockall scores in predicting prognosis of patients presenting to emergency department with upper gastrointestinal bleeding. Scand J Trauma Resusc Emerg Med. 2015;23:109. doi:10.1186/s13049-015-0194-z.

16. Russo RM, Williams TK, Grayson JK, Lamb CM, Cannon JW, Clement NF, et al. Extending the golden hour: partial resuscitative endovascular balloon occlusion of the aorta (P-REBOA) in a highly lethal swine liver injury model. J Trauma Acute Care Surg. 2016:80:372-80. doi:10.1097/TA.0000000000000940.

17. Brenner ML, Moore LJ, DuBose JJ, Tyson GH, McNutt MK, Albarado RP, et al. A clinical series of resuscitative endovascular balloon occlusion of the aorta for hemorrhage control and resuscitation. J Trauma Acute Care Surg. 2013; 75:506-11. doi:10.1097/TA.0b013e31829e5416.

\section{Submit your next manuscript to BioMed Central and we will help you at every step:}

- We accept pre-submission inquiries

- Our selector tool helps you to find the most relevant journal

- We provide round the clock customer support

- Convenient online submission

- Thorough peer review

- Inclusion in PubMed and all major indexing services

- Maximum visibility for your research

Submit your manuscript at www.biomedcentral.com/submit

) Biomed Central 